SITES: NEW SERIES - VOL 13 NO $2 \cdot 2016$

DOI: http://dx.doi.org/10.11157/sites-vol13iss2id317

- ARTICLE -

\title{
NEW ZEALAND STUDENTS AND ‘CULTURES OF INTOXICATION’
}

\author{
Fiona Hutton ${ }^{1}$
}

\begin{abstract}
The drinking practices of New Zealanders have been the subject of much concern, culminating in a report by the New Zealand Law Commission in 2010 which presented evidence-based recommendations for implementing effective alcohol policies in New Zealand. Within debates about alcohol consumption and drinking practices New Zealand University students have been identified as a group of young people who drink more heavily than their peers, as well as suffering from more alcohol related harms.
\end{abstract}

The following discussion focuses on a group of eight university students, aged 18-19, some who were non- or light-drinkers, and their reflections on the cultures of intoxication that they negotiate, as well as their experiences of peer pressure. The aim of this article is to discuss the drinking and abstinence practices of this group of New Zealand university students to explore how they interact with or resist contemporary cultures of intoxication in the particular context of university life. Eight qualitative, semi-structured interviews were thematically analysed and the themes: cultures of intoxication, peer pressure and inexperienced 'drinking disasters' are discussed. This paper critically explores these key themes and discusses the New Zealand context in relation to the international literature about student drinking cultures (Hernandez, Leotini and Harley 2013; Romo 2012; Supski, Lindsay and Tanner 2016), including young people who are light or non-drinkers (Conroy and de Visser 2014; Narin, Higgins, Thompson, Anderson and Fu 2007; Fry 2010; Herring, Bayley and Hurcombe 2014). The interviews identified an overarching New Zealand culture of intoxication, as well as more local cultures of intoxication, which students bring with them to a university setting.

Keywords: Alcohol; students; cultures of intoxication; harm reduction 
INTRODUCTION

The broad aim of this article is to discuss the drinking and abstinence practices of a group of eight New Zealand university students (aged 18-19 years) to explore how they interact with or resist contemporary cultures of intoxication in the particular context of university life. This discussion of young students' experiences is situated within the academic debates focusing on contemporary cultures of intoxication (Griffin, Bengry-Howell, Hackley, Mistral, and Szmigin 2009; McEwan, Campbell, Lyons, and Swain 2013; Measham and Brain 2005), as well as scholarship noting that not all young people engage in heavy drinking (Conroy and de Visser 2014; Fry 2010, Herring, Bayley, and Hurcombe 2014; Nairn, Higgins, Thompson, Anderson, and Fu 2007).

New Zealand, in common with many other westernised countries, has a welldeveloped 'culture of intoxication'. While drinking to excess has an historical legacy (Eldred-Grigg 1984; Hutton 2009), in the last ten years or so different ways of drinking are argued to have emerged, marked by the 'culture[s] of intoxication that now sustains this drinking behaviour' (McEwan et al. 2013, 35). The term culture of intoxication is used here to acknowledge that there are clear, culturally embedded celebrations of alcohol and intoxication, firmly enmeshed in the social life of many countries, New Zealand included. As Douglas $(1987,4)$ notes, alcohol consumption is an expression of culture: 'a highly patterned, learned comportment which varies from one culture to another' In a New Zealand context alcohol is consumed in both informal and formal gatherings and its consumption is integrated into many different kinds of occasions e.g., birthdays, marriages, deaths, passing exams. Drinking as a means to relax, to bond relationships and to have a good time is positively encouraged along with extensive promotion of alcohol in New Zealand society. However, while an overarching New Zealand culture of intoxication can be identified there are a diverse range of more localised cultures of intoxication related to age (Emslie, Hunt and Lyons 2012), ethnicity (Hutton and Wright 2015), gender (Griffin, Szmigin, Bengry-Howell, Hackley, and Mistral 2013; Hutton, Wright, and Saunders 2013; Lyons and Willot 2008), socio-economic status (Bailey 2012; Day, Gough and McFadden 2003; Ross-Houle, Atkinson, and Sumnall 2015), geographical location and so on. Intoxication through alcohol consumption is noted here as a process of social interaction that is performed according to particular sets of norms and values dependent upon an individual's social and cultural context. Thus, although an overarching 'culture of intoxication' can be identified, alongside the historical embeddedness of alcohol intoxication in social and cultural interactions, it must also be acknowledged that not all New Zealanders partake in this culture of intoxication. The phrase 'culture 
of intoxication' is used here to emphasise the pervasiveness of alcohol in contemporary New Zealand society, and the expectation that people will engage with social and cultural norms to consume alcohol. In using the term 'culture of intoxication' the suggestion is not that it is a static entity. The term is used instead to refer to a fluid, changeable set of norms and values that inform people's drinking practices. Groups and individuals may move along a continuum of engagement with this pervasive alcohol culture: some may engage wholeheartedly, others more moderately, others still, not at all. Therefore, individuals have agency within, interact with, and resist the cultures of intoxication that they are surrounded by.

Although individuals may shape the cultures of intoxication they interact with, the national New Zealand culture of intoxication often dominates this interaction. For example, it is argued that contemporary drunken behaviour amongst some groups is considered socially acceptable (McEwan et al. 2013). Scholars in this area have identified what they term a 'determined drunkenness' on the part of young people who indicate that drunkenness is a desired state, seen as pleasurable, sociable and fun (Measham and Brain 2005). The contemporary culture of intoxication in recent decades is therefore marked by distinctive indicators: who is drinking to intoxication, what behaviour is acceptable while intoxicated and why drinkers are drinking to intoxication (McEwan et al. 2013, 38). The historical development of New Zealand drinking identities such as those relating to the performance of masculinities (Philips 1987), femininities (Hutton et al. 2013), ethnicity (Hutton and Wright 2015), and the subsequent overarching contemporary culture of intoxication rest partly on the notion of reiteration (Butler 1990): the constant repetition of alcohol and intoxication as part of 'everyday' celebrations and social events, fuelled by greater access to and availability of alcohol. A contemporary culture of intoxication has therefore been identified by scholars in this area (Brain 2000; Measham and Brain 2005). The liberalisation of alcohol policy enshrined in legislation such as the New Zealand 1989 Sale of Liquor Act, began the process of opening up access to and availability of alcohol by relaxing licensing laws, and increasing the diversity of places that could sell alcohol products. These policy shifts have occurred alongside, and helped to facilitate, the development of the night-time economy (NTE). It is further argued that this has signified a move into a 'new alcohol order' (Brain 2000), with the commodification of both leisure and pleasure, and an emphasis on public intoxication and drunkenness (Measham 2006). Therefore the term 'culture of intoxication' used in this discussion, refers to the combined developments in legislation and policy that have facilitated particular drinking practices in the NTE, influenced by a diverse range of social and cultural factors, including the availability of cheap alcohol and the rise 
of social media as a largely unregulated advertising space for alcohol companies (McCreanor, Lyons, Griffin, Goodwin, Moewaka Barnes, and Hutton 2013; Moeweka Barnes, McCreanor, Goodwin, Lyons, Griffin, and Hutton 2016; Nicholls 2012). Added to this is the rapid development of alcohol advertising and marketing, particularly to young people, leading to the development of 'intoxigenic environments' (McCreanor, Moewaka Barnes, Kaiwai, Borell, and Gregory 2008) into which young people are socialised: learning and observing wider drinking norms that are reiterated on a regular basis by parents, the media, alcohol marketing and peers. Scholarship in a New Zealand context has also noted that particular populations such as young people and university students engage enthusiastically with the NTE where intoxication is a desired and sought after state (Hutton 2012; Kypri, Paschall, Langley, Baxter, CashellSmith, and Bourdeau 2009; Kypri, Langley, McGee, Saunders, and Williams 2002). This article seeks to add to these debates, exploring how this emphasis on alcohol consumption is experienced by a specific group of young people: university students.

University students, the focus of this study, are a group who are identified as drinking more heavily than their peers and as suffering from a higher rate of alcohol related harms (Hernandez, Leontini, and Harley 2013; Karam, Kypri, and Salamoun 2007; Kypri et al. 2002; Kypri, Paschall, Langley, Baxter, and Bourdeau 2010; Wechsler, Lee, Kuo, Seibring, Nelson, and Lee 2002). Scholarship focussing on students drinking practices has identified a culture of intoxication particular to university students (Hernandez, Leotini, and Harley 2013; Karam et al. 2007; Kypri et al. 2002; Kypri et al. 2010). As Supski, Lindsay, and Tanner $(2016,5)$ note 'drinking is seen by university students as a routinized, socially expected part of university life'. Students themselves identify that heavy alcohol consumption is a feature of being at university (Hutton 2012). Therefore, although it could be argued that student drinking is similar to the drinking practices of other groups of young people, it is noted here that student cultures of intoxication are a distinct subset of wider youth drinking cultures with a more intense focus on the pleasure, fun and sociability associated with heavy consumption of alcohol (Hernandez et al. 2013; Hutton 2012; Karam et al. 2007; Kypri et al. 2002; Kypri et al. 2010). Furthermore, students, particularly those living in halls of residence, are in a unique situation, away from parental constraints for the first time and surrounded by those of a similar age. However, students may also shape, resist and interact with the cultures of intoxication encountered in this particular cultural context, they are not necessarily passive in their engagement with drinking cultures. 
The effects of a cultural and social shift towards a neo-liberal social context in many westernised nations is argued to have shaped contemporary cultures of intoxication with a drive towards consumption, individualisation and excess (Bailey 2012; Measham and Brain 2005). The notion of the 'free' liberated individual making choices about intoxication is inherent in much of the discourse about young people's drinking. However as noted by Griffin et al. (2009) social groupings and belonging are still important in this neoliberal landscape. In fact, it is argued that social groups such as drinking friends may be highly significant in this shifting landscape, given that institutions such as the family have been eroded as sources of care and intimacy in the last forty years or so (Griffin 2009 et al., 215). Therefore sociological approaches emphasising the wider social context often challenge neo-liberal, individualised discourses, presenting alcohol researchers with some difficulties (Lunnay, Ward, and Borgladan 2011): there is more than the individualised, consumer orientated, neo-liberal ideal contained within young people's drinking practices.

In exploring the debates surrounding young people and their interactions with the 'new alcohol order' (Brain 200o), Abel and Plumridge (2004) note that 'alcohol consumption has become almost mandatory for sociability among young New Zealanders' (cited in Nairn et al. 2007, 288), where it has an important function (Gordon, Heim, and MacAskil 2012). Alcohol consumption possesses an important symbolic meaning for young people (Ross-Houle et al. 2015), and consuming alcohol is also a signifier in terms of identity and fitting in to the social norms of particular groups. Alcohol is described as 'decisive' for teenagers' status within their social groups (Järvinen and Gundelach 2007, 55), and positioned as a 'symbolically significant activity with the potential to create and maintain social distinctions between youths' (Järvinen and Gundelach 2007, 55). International research has also noted the importance of drinking in friendship group bonding through shared stories of nights out (Griffin et al. 2009; Sheehan and Ridge 2001; Tutenges and Sandberg 2013), and that 'drunkenness is a required condition of drunken nights out' (Christmas and Seymour 2014, 6). Additionally, the rise of the consumption-orientated night time economy (NTE) has meant that for young people engagement with these cultures of intoxication is 'an all but compulsory aspect' of their lives (Griffin et al. 2009, 226).

Intoxication has therefore been identified as a core group bonding activity with alcohol performing a symbolic function, related to symbolic capital in young people's peer groups. Bourdieu's (1989) notion of 'symbolic capital', defined as 
'anything recognised by social agents as having value in a social context that affords the individual prestige, honour and a bolstered social status' (cited in Lunnay et al. 2011, 431), is useful in considering young people's drinking within the overarching cultures of intoxication. In particular the idea that drinking alcohol (or the appearance of drinking alcohol) performs an important symbolic function through the attainment of symbolic capital in young people's peer groups, is particularly relevant in young people's drinking practices both internationally and in New Zealand (Demant and Järvinen 2011; Griffin et al. 2009; Hernandez et al. 2013; Hutton 2012; Hutton et al. 2013; Szmigin et al. 2008). Being a 'drinker' is argued to be highly important in young peoples' social interactions, with experienced drinkers gaining a high degree of symbolic capital (Järvinen and Gundelach 2007). Symbolic capital in these interactions does not necessarily refer to alcohol consumption per se, rather the successful consumption of alcohol needs to be achieved leading to the attainment of symbolic capital. The function of alcohol consumption: the inter/intrapersonal, ritual, intoxication functions that drinking occasions fulfil' (Gordon et al. 2012, 8 ) is thus argued to be critical in young people's drinking friendship groups. Therefore, an exploration of young people's cultures of intoxication needs to consider 'how their individual actions respond to and interact with these wider social structures' (Lunnay et al. 2011, 431), and this article aims to explore some of the issues related to young people and alcohol consumption within the wider culture of intoxication. However, it is also acknowledged here that although drinking is often central to young adult's lives, drunkenness is not necessarily part of their drinking practices (Zajdow and MacLean 2014). A growing body of recent research has noted that young people actively construct identities that do not involve heavy alcohol consumption, and that a sizeable minority of young people abstain from drinking alcohol (Conroy and de Visser 2014; Fry 2010; Herring, Bayley, and Hurcombe 2014, 2). Further, young people have agency in their interaction with cultures of intoxication, they are not simply passive in their responses to and engagement with drinking cultures.

YOUNG PEOPLE AND ABSTINENCE FROM ALCOHOL

Despite the rise of the NTE (Hadfield 2006; Hutton 2009; Measham and Brain 2005), the contemporary culture of intoxication (McEwan et al. 2013), and the importance of alcohol in young people's friendship groups, recent drinking statistics have highlighted some significant issues. In New Zealand in 2013, although hazardous drinking was most common among men and women aged $18-24$, the rate of hazardous drinking in this age group had decreased since 2006/07 (Ministry of Health 2013). The Youth '12 survey also noted that young people aged between $13-18$ had reported a significant decline in alcohol (as 
well as tobacco and cannabis) consumption since 2001 (Clark et al. 2013, 24). Similar trends have been noted in other countries such as the UK and Australia (Fuller 2010; Fuller and Hawkins 2013; Livingston 2011; Measham 2008), indicating that some groups of young people at particular developmental stages are drinking less than those in these age categories in the past. In a New Zealand context Nairn et al. (2007) and Suaalii-Sauni, Suma, Dunbar, Pulford, and Wheeler (2012) also discuss groups of young people who are non or light drinkers and argue that young people who do not drink are often a neglected group, with research focusing on problematic alcohol consumption. Additionally, researchers have noted that young people who abstain from drinking are an important group to consider. Their reasons for not drinking could provide some 'ways in' to effective harm reduction interventions with their peers who do drink, and gaining insights into how young people construct non-drinking identities is also valuable (Nairn et al. 2007).

Although, this is not to suggest that harms from alcohol consumption have vanished among youth populations. Babor et al. (2010) for example, notes that young people who drink, consume alcohol to intoxication more frequently than other age groups, and that there are significant harms related to young people's alcohol consumption such as: violence, injury, unwanted sex, alcohol poisoning and absenteeism as well as longer term health problems. Livingston $(2014,927)$ further notes that although abstinence rates have increased amongst Australian teenagers, the harms from alcohol consumption have also increased, suggesting that harm and consumption trends are more concentrated amongst particular groups. Therefore, the debates surrounding young people's drinking are complex and contradictory. The divergence of drinking patterns in high income westernised countries has been the subject of recent scholarly attention (Livingston 2014; Measham 2008), as have groups of young people such as university students who are light or non-drinkers (Conroy and de Visser 2014; Nairn et al. 2007; Romo 2012; Supski et al. 2016). Therefore, although peer pressure and the influence of social norms are related to young people's drinking, gaining a better understanding of non-drinkers' experiences in a university setting might be useful in unsettling and challenging these kinds of pressures (Conroy and de Visser 2014). There are also significant challenges for young people who position themselves as non-drinkers, generally as well as in specific contexts such as university, including: 'social condemnation and isolation from their peers' (Järvinen and Gundluch 2007, 68); being seen as a party killer, prudish, not fun, and not desirable to 'hang out' with (Romo 2012); being called on to explain their non-drinking, experiencing peer pressure to drink (Conroy and de Visser 2014). Exploring the drinking practices and experiences of young people who are heavy drinkers, as well as those 
who are or non-or light drinkers may provide valuable insights within these complex debates. The study reported on here aims to give some insights into the experiences of both heavy and light or non-drinkers as they negotiate the cultures of intoxication present in their lives, and the pressures on them to consume alcohol within a university setting.

\section{STUDENTS, ALCOHOL AND CULTURES OF INTOXICATION}

This exploratory study focuses on the tensions and contradictions inherent in the shifting social and cultural context of a small group of young New Zealand university students. In particular the discussion centres on the rise of contemporary cultures of intoxication and what these mean for the young people who negotiate them, alongside the symbolic capital of alcohol consumption and its function (Gordon et al. 2012, 8). The tensions in the contradictory discourses surrounding young people's drinking, often overlooked in research with young people, are what this article seeks to explore within the broader social context of intoxication as a cultural norm (Bailey 2012; Demant and Järvinen 2011; Griffin et al. 2009; Tutenges and Sandberg 2013). This normative consumption of alcohol is particularly evident for university students, with researchers in New Zealand and internationally noting a heavy drinking culture present in university settings (Conroy and de Visser 2014; Hernandez et al. 2013; Hutton 2012; Kypri et al. 2010; Romo 2012; Supski et al. 2016). The complexity of the cultures of intoxication that young people interact with are often neglected in the debates surrounding young people and alcohol consumption. For example, the diversity of drinking cultures that students bring with them to the university setting is often unacknowledged. Furthermore as Nairn et al. (2007) note, young people who do not drink are often a neglected population. This article focuses on the experiences of students who are both drinkers and nonor light drinkers, addressing in part a gap in the academic scholarship in this area. More specifically, the research questions this discussion will explore are a) how do young drinkers negotiate or resist the culture or cultures of intoxication that they are surrounded by? b) what factors influence engagement with the culture or cultures of intoxication? c) what harms are associated with this sample's drinking practices in this particular social and cultural context?

\section{METHODS AND METHODOLOGY}

The interviews discussed here were part of a wider research project, carried out in 2010, exploring the use of a harm reduction intervention during student orientation. The project was supported by the Victoria University Reduce Harm Group (VURHG), a multi-disciplinary group that focuses on interven- 
tions during orientation for first year students, who are noted by accommodation managers and student health services as particularly vulnerable to harms from intoxication. vURHG developed a competition for students attending the 'zombie' party during university orientation. All students who blew under the drink driving limit (which in New Zealand at this time was $400 \mathrm{mcg}$ breath or $80 \mathrm{mg}$ blood) went into the draw to win an i-Pad. The aim was to try to reduce pre-loading before the event. A questionnaire was administered to 271 students arriving at the event, after they had been breathalysed, asking them if the breathalyser competition had an effect on their drinking, how much alcohol they had consumed, where they had consumed it and some general information about their drinking practices e.g. how much they usually drank. The questionnaire also called for volunteers to be interviewed about their drinking practices. Nineteen gave their details and when contacted, eight agreed to be interviewed. These interviews are the focus of this article. Participants were asked in more detail about the breathalyser and to talk about their ideal night out, as well as any risks they or their friends took whilst out drinking.

As with all studies there are some important methodological limitations that need to be noted. To begin with the sample is small with only eight participants, and this makes it difficult to make any definitive statements from the data. The sample is also quite diverse: four non or light drinkers; three heavy drinkers, and one who is in between, increasing the difficulty in drawing definitive conclusions from the interview data. Small scale, exploratory, qualitative studies of this nature cannot claim to speak for all young drinkers or abstainers, although rather than aiming for representativeness the study aimed to explore some of the meanings that engaging with student cultures of intoxication had for participants. However, the value of qualitative data of this nature is in the insights gained into particular practices. Such insights are valuable in considering avenues for further research and in providing a nuanced discussion of participants' drinking practices. The sample also self-selected to be interviewed and is therefore a very specific group of young people, drawn from a sample of university students who are also noted as a population who drink more heavily than the general population (Karam et al. 2007; Kypri et al. 2010; Wechsler et al. 2002). This could affect the data, skewing towards heavier drinkers' stories. However, what is interesting about these particular interviews is that half of the sample were non-or light drinkers, suggesting that the homogenous view of students as heavy, risky drinkers is perhaps not entirely accurate.

In analysing the interviews, close reading of the transcripts was employed and a thematic approach taken (Braun and Clarke 2006). The focus was on participants' talk about their experiences of drinking and abstinence within cultures 
of intoxication, and key themes were identified using the research questions as a lens. The aim was to identify similarities and differences across the data set in order to generate insights from the themes and to extract concepts and theory from the data (Bryman and Burgess 1994). The three themes discussed throughout this article were developed from the most common issues identified across all eight interviews. Common similarities were identified throughout all the interviews including peer pressure to consume alcohol, as well as several differences such as the amount of alcohol consumed, or the extent of experience in consuming alcohol.

The interviews were conducted by the author at a private room in the university, and lasted approximately 60 minutes. They were audio-recorded with permission, for ease of transcription. Ethical approval was granted by Victoria University of Wellington's ethics committee. All respondents signed a consent form and received a NZ\$2O supermarket voucher to thank them for their participation. Confidentiality was maintained by both the interviewer and the transcriber (who signed a confidentiality agreement). Pseudonyms are used to identify respondents in the following quotes, as well as gender and age.

\section{RESULTS AND DISCUSSION}

Table 1 summarises the demographic characteristics of the interviewees and categorises them in relation to their drinking practices as; 'non-binge' (1-4 drinks); 'binge light' (5-8 drinks); 'binge moderate' (9-12 drinks); and 'binge heavy' (13-18+ drinks), (Hutton 2012, 231).

Table 1. Participants and number of drinks

\begin{tabular}{l|l|l|c|c|c}
\hline Pseudonym & Gender & $\begin{array}{l}\text { Consumption } \\
\text { category }\end{array}$ & Age & $\begin{array}{c}\text { No. drinks }{ }^{2} \text { on a } \\
\text { 'casual' night out }\end{array}$ & $\begin{array}{c}\text { No. drinks on a } \\
\text { 'big' night out }\end{array}$ \\
\hline Cassie & Female & Non-binge & 18 & $1-2$ & $1-2$ \\
\hline John & Male & Binge heavy & 18 & $3-4$ & $13-15$ \\
\hline Ben & Male & Binge heavy & 18 & - & $18+$ \\
\hline Jane & Female & Non-drinker & 18 & 0 & 0 \\
\hline Grace & Female & Binge moderate & 18 & $5-6$ & $7-8$ \\
\hline Nicola & Female & Binge heavy & 18 & $1-2 / 3-4$ & $9-10 / 13-15$ \\
\hline Jake & Male & Binge light & 19 & - & Up to 6 \\
\hline Jennifer & Female & Non-binge & 17 & $1-2$ & $3-4$ \\
\hline
\end{tabular}


In order to explore how this sample of young students talked about their drinking, and the issues that shape their drinking practices, the following three themes will be discussed: cultures of intoxication, peer pressure, inexperienced 'drinking disasters'.

\section{Cultures of intoxication}

All eight of the interviewees noted that a drinking culture was present amongst university students which included norms and values that emphasised heavy drinking practices, although as Table 1 demonstrates the amount of alcohol they consumed varies considerably. The interviewees focused on discussing their drinking practices and their negotiation of the wider cultures of intoxication surrounding them. Cassie reflected on the fact that most of her friends drank more heavily than she did, and stated that she disliked not 'being in control. I would rather just not drink too much', in accounting for her own 'non-binge' drinking practices. Jane referred to the culture of intoxication that surrounds her in her family and states that her being a non-drinker 'annoys my parents' who try to pressure her into consuming alcohol. She also notes that her position as a non-drinker is 'unique-ish because lots of people my age do drink, a lot and I don't' but that she 'probably will [get drunk] one day. I mean I'm at university'.

So even though Jane has resisted the culture of intoxication thus far, she acknowledges that this may change in the future due to the student drinking culture at her university. Her reflections highlight how young people's drinking is a fluid process, and that a drinking or non-drinking identity is not necessarily fixed. As Livingston (2014) notes teenage abstention rates often decline with age. As young people engage more intensively with the NTE and its expectation and celebration of alcohol consumption, previous drinking practices may change or adapt. In peer groups where the symbolic capital of alcohol consumption is high, the pressure to drink may become unavoidable. Those who refrain from drinking may also find themselves on the margins of their friendship groups, therefore either presenting a false drinking persona or engaging with drinking cultures may also become be unavoidable options (Griffin et al. 2009). As noted earlier, the function of alcohol is important in young people's drinking friendship groups (Griffin et al. 2009), as well as being emphasised in the wider culture of intoxication with alcohol consumption often situated as cultural norm.

John (male, binge heavy, 18) also reflects on student cultures of intoxication in the university halls of residence, where people drink to excess because they 
think it makes them look cool', and that a core group of 'cool guys I guess' drink to become heavily intoxicated. For some this enhances their reputation, but for others who "have just discovered alcohol and are like "this can make me cool" ...they always end up on the floor at 1opm', the opposite is true. He recognises the symbolic capital (Bourdieu 1989) associated with successful heavy drinking and that this can be enhanced or reduced in such instances. Alcohol therefore plays an important function (Gordon et al. 2012) in these scenarios, marking belonging to a particular group, which is dependent on the level of symbolic capital attained.

The drinking culture in small towns was often described as being worse than in the capital city, with no culture of casual, social drinking, and an emphasis on heavy alcohol consumption. Participants who came from outside of Wellington noted the influence of the drinking culture in their home-towns, and referred to some of the issues involved in negotiating the culture of intoxication that they are surrounded by. The following quotes demonstrate the symbolic importance of alcohol within different drinking cultures. Alcohol performs a particular and visible function in different communities, reiterating (Butler 1990) drinking to get drunk as commonplace everyday practices:

Like I'm from a small town and this is not an excuse but there is quite a really heavy drinking culture so I guess even in 6th form I would drink till I spewed [vomited] or things like that. I have been sick once this year from drinking. I don't black out or things like that... Yeah, there doesn't seem to be any like 'just go out for a casual' ...there's no limit like, go out for 4 drinks, it's like drink a box like a 12 pack or drink 2 boxes or drink a lot of vodka. There is no stopping. (Nicola, binge heavy, 18)

This participant recognises that the culture of intoxication in her home-town differs from other places. She also blames this particular drinking culture for her earlier risky drinking practices with the reiteration of heavy drinking norms and values affecting her experiences of alcohol consumption. She identified older adults as regular drink drivers, emphasising the wider New Zealand culture of intoxication that often pervades young people's lives:

I mean it's the same getting pissed culture...there's so many people that drink drive you know and I guess the 35-40 year olds, there's just heaps of people that drink drive in [names place], and you know they'll just get plastered at the pub and drive down the road. (Nicola, binge heavy, 18) 
In the following quotes heavy drinking is also related to drinking games in an expression of masculine drinking norms and values:

Where I'm from there's like two and a half thousand people, and it's just ...the guys are hard-core, and the girls are just as bad as the guys. It's a real sort of rugby culture and drink as much as you can. They did a 50-litre keg in 49 minutes. There was like a group of them and they did that ...just some of the drinking games as well ...just kind of disgusting.

Interviewer: Can you describe them to me?

You probably don't want to know! There's this thing it's called a bum funnel and two guys stand there, pull their pants down, put their cheeks together and another guy will be underneath and they pull the beer down through the cracks in their ass and they drink it! (Nicola, binge heavy, 18)

Expressions of masculinity are often associated with drinking and drunkenness (de Visser and Smith 2007; Graham and Wells 2003), and it could be argued that traditional, forceful ways of doing (hegemonic) masculinity (Connell 1995) are evident in such drinking games. Furthermore, such drinking games and their power to bestow symbolic capital often engender heavy, risky drinking practices, encouraging heavy drinking sessions that are celebrated via SNSs and social media channels, intensifying the difficulty of successful harm reduction interventions (McCreanor et al. 2008; Nicholls 2012). The quotes above also demonstrate that young people are responding to and interacting with a wider culture of intoxication that surrounds them, although Jennifer below was highly critical of the New Zealand drinking culture:

Yeah I think the drinking culture in New Zealand is ridiculous. Like people say we're bad but who did we learn that from? They [her parents/parents of friends] actually set up a big boycott [referring to school ball] because they couldn't drink and to me it was like, well, no wonder we're bad if you are like that. (Jennifer, non-binge, 17)

The drinking practices of significant adults in young people's lives impacts heavily on their drinking practices (Nairn et al. 2007; Suaalii-Sauni et al. 2012), and influenced participants' (non)engagement with cultures of intoxication. Jennifer is highly critical of her parents and sets herself apart from seeing alcohol as a necessity and restricted access to it as something to protest about. 
As Herring et al. $(2014,101)$ note, young people who chose not to drink are often angered by the lack of support for their choice. Jennifer also made the point that most of her friends were not yet eighteen at the seventh form ball so if the school did allow alcohol it would be condoning underage drinking, emphasising the wider cultures of intoxication that young people experience and negotiate. The intrusion of the New Zealand culture of intoxication into young people's lives, noted by Jennifer and Nicola, illustrate that students' drinking cultures do not develop in a vacuum. University students' drinking cultures have developed, and sit within, wider overarching cultures of intoxication, driven by social and cultural changes in alcohol consumption, legislation and the NTE (Hutton 2009; McEwan et al. 2013; Measham and Brain 2005).

Additionally, the quotes also indicate that students bring with them the drinking culture that they have already been socialised into. Therefore it could be suggested that in university halls there are a diverse set of drinking practices that young people need to try to negotiate and merge with or challenge and resist. However, merging with the dominant cultures of intoxication may be challenging, especially if they are significantly different compared to cultures of intoxication previously experienced. Ways of being and doing whilst consuming alcohol vary, and are dependent upon social and cultural context. Therefore, for young people in particular, the drinking practices of their peers is of critical importance.

\section{Peer pressure}

The negotiation of the wider culture of intoxication and local student drinking cultures was problematic for all interview participants, not only those who did not drink or preferred not to drink. Alcohol consumption is noted as central to teenage identity construction (Järvinen and Gundelach 2007), with university halls of residence often sites of increased consumption for most new students (Conroy and de Visser 2014; Hutton 2012; Romo 2012; Supski et al. 2016). Non or light drinkers are often perceived as being 'outside the norm' (Herring et al. 2014,101 ) which is uncomfortable for young people whose peer group is often of crucial importance (although it is recognised here that some young people are happy to be different from the crowd).

International research has noted the centrality of alcohol in youth peer groups, and as Griffin et al. (2009) argue, friendship groups, consisting of known others who are socialised with during drinking occasions, are crucial in this respect. However, for first year university students many of whom have just moved away from these known and trusted friendship networks, the pressure 
to fit in and find new friends to socialise with is intensified. A UK study with students who were non-drinkers found that concealing a non-drinking identity was desirable amongst new acquaintances, due to negative reactions (Conroy and de Visser 2014) intensifying the problems for new university students who were non-drinkers. US students also described that their non-drinking status made it harder for them to connect with drinking peers (Romo 2012). Peer pressure was therefore identified as a key issue for all the research participants, which influenced their engagement with student, as well as wider, cultures of intoxication:

Yeah I feel peer pressure to drink more 'cause my friends are aware that I don't drink much and they're like 'oh you should get loose, get drunk, have a shot' and I'm like 'no I'm fine'. I've just never really been with that sort of culture and it's just weird to me that you'd want to do that. (Cassie, non-binge, 18)

Yeah it was peer pressure really, I was 17 at the time, I drank a goon sack $^{3}$....it was mass peer pressure really. If you are not drinking you are weird. (John, binge heavy, 18)

I guess it's just students. It's just what they do what they are kind of expected to do. What the whole, I dunno, the kind of pressure to perform and do what everybody else is doing ...someone says 'drink, drink!' and you're like 'oh, ok'. (Grace, binge moderate, 18)

What was interesting in the interviews were the comments from non-or-light drinkers about how they appeared to engage with the culture of intoxication whilst successfully staying at the margins. While peer pressure to engage with the culture of intoxication was problematic, some participants managed to present a drinking identity without having to drink heavily. For example, Jake below disguises the fact that he does not drink heavily by just having 'a couple yet is recognised as a drinker by others. Concealing or being vague about his non-drinking identity minimises the potential social risks associated with being publicly identified as a non-drinker (Romo 2012, 679). As Järvinen and Gundelach $(2007,68)$ note it is the cautious drinkers who risk social condemnation and isolation from their peers'. Jake recognises the symbolic capital attained by imitating a heavy drinking identity so he actively seeks to present such a drinking persona, merging with this particular culture of intoxication, although he stays at the margins, compared to others in his peer group:

There is [sic] a couple of people at the Hostel [university student hall 
of residence], they kept trying to get me to drink at the hostel but if I do I only have a couple and I just chill out with them ...but yeah. They tend to get real hammered. (Jake, binge light, 19)

Jane in the quotes below also recognised the symbolic capital associated with alcohol consumption, and she merges with the student culture of intoxication, by passing herself off as a drinker:

Interviewer: So you would drink alcohol in that situation?

No, not usually. Because I don't really like it, to be honest. And if I do drink, it's usually like one RTD and I usually fill it up with like Sprite and drink that so no-one like, picks on me, stop the peer pressure

Interviewer: So you do feel a bit of peer pressure to drink alcohol?

Yeah, a lot. (Jane, non-drinker, 18)

Therefore the students interviewed wanted to be seen as drinkers to fit into student cultures of intoxication, without actually consuming any, or very little, alcohol. So they wanted to be seen to 'drink in the right way' (Demant and Järvinen 2011, 10) in order to present a successful persona to their peers. Alcohol is therefore a symbolic marker of group identity: its function is to establish young people as part of drinking and friendship groups. By consuming alcohol, or appearing to do so, young people gain symbolic capital within student cultures of intoxication. The reasons for non-drinking have also been identified as important (Conroy and de Visser 2014). Culturally unsanctioned reasons for non-drinking, like those noted by Jane ('I don't really like it to be honest'), means that unsanctioned drinkers face more peer pressure to consume alcohol compared to those who have 'good' reasons such as being on medication or religious reasons (Conroy and de Visser 2014, 538). Therefore, those who are non-drinkers are discouraged from disclosing their non-drinking status to peers for fear of negative consequences. However, although they were not actively identifying as non-drinkers, some of the students in this study did resist the dominant group norms to drink heavily and shaped alternative ways to interact with student drinking cultures. To this end those who did not drink or preferred not to drink noted some interesting strategies to 'pass' as a drinker, to avoid the pressure from others:

Like I said I'm not like anti it, I just don't want to do it to the extent that everyone else seems to, and so yeah ...it's safer if you just say: 
'yes' when someone offers you one and drink it slowly and say when someone else offers you one: 'I've still got one, it's cool'. And then you are less likely to get the flak that goes with the whole avoidance technique. (Jennifer, non-binge, 17)

Although this participant also drinks grape juice instead of alcohol which looks like champagne or sparkling wine:

Or drink something that looks like you are drinking. I think grape juice works quite well I've discovered ...the other day someone said: 'oh, you're drinking champagne' and I was like: 'oh ...yeah!' They are like: 'cool' and just kept walking. I'm like: 'sweet'. (Jennifer, non-binge, 17)

This was also a strategy employed by another non-drinker who, at her school ball, drank sparkling grape juice to make it look like she was drinking champagne:

I just generally grab a bottle of sparkling grape juice and drink that. It looks the same [as champagne]. (Jane, non-drinker, 18)

This participant has also used other strategies to disguise her non-drinking:

Pick[ed] a whole lot of labels off Schweppes ginger beer and stuck like other labels on from alcohol bottles and we just used to save bottles to like put fizzy in them. (Jane, non-drinker, 18)

In order to avoid the peer pressure described earlier, those who do not drink or are light drinkers go to extraordinary lengths to 'pass' as drinkers. Fry (2010, 1289) also noted what she describes as a 'veil of secrecy' in relation to young people's decisions to integrate with the dominant drinking culture. Her respondents also avoided opposing group norms around drinking through ruses such as holding a drink for long periods of time, and filling up alcoholic drinks with water or soft drinks to disguise their light or non-drinking. In a New Zealand context, this emphasises the wider national, as well as a more local student, culture of intoxication. The behaviour of peers, and pressure to conform to heavy drinking patterns were key factors in participants' decisions to engage with, or at least give the appearance of engaging with, student drinking cultures. These strategies also emphasise the importance of alcohol in signifying a particular successful [drinking] identity, and that presenting a drinking identity is a necessary aspect of belonging to a peer group in this context. Although as 
Nairn et al. (2007) argue, while 'passing' is often not seen as challenging the status quo, these students are resisting the pressure to drink, drink excessively or to intoxication, while presenting a drinking 'front' to their friends, shaping their engagement with student drinking cultures.

\section{Inexperienced 'drinking disasters'}

Participants also identified a number of harms (as well as the previously discussed benefits offered by symbolic capital, peer bonding and sociability) associated with alcohol consumption ranging from being out of control, to speed consumption of large amounts of alcohol, vomiting and blackouts. For this sample these harms were largely driven by engagement with the culture of intoxication with the emphasis on heavy drinking as a national cultural norm in New Zealand (McEwan et al. 2013). A common theme throughout the interviews about drinking harms, related to the socialisation of young people into this culture of intoxication, was 'drinking disasters' and inexperienced drinkers. Participants noted that their peers who were new to drinking often had 'drinking disasters' due to their lack of experience with alcohol consumption, resulting in a lack of symbolic capital:

Like this girl who chucked up in the sink the other day. But she'd never really drunk. I think that was the first time she'd drunk actually and she'd sculled ${ }^{4}$ a bottle of wine and she threw up in the sink, which is not ideal. (Nicola, binge heavy, 18)

No, the blackouts freak me out 'cause there was this guy who fell, I don't know if he fell asleep or whatever, outside someone else's flat on our floor and what freaked me out more was that his friends left him there, and these are really decent guys as far as I'm concerned and they were talking about how funny it was that they left him and I was like: 'what, why did you leave him there?' They've got photos of him there, and they left him there! (Jennifer, non-binge, 17)

When an inexperienced drinker meets local student cultures of intoxication, the mixture of inexperience and the often 'go hard' attitude towards alcohol consumption contributes to these kinds of harmful 'drinking disasters' or 'symbolic failures'. For students starting university who have not had a lot of exposure to 'alcohol or partying and things like that' they tend to be the ones who 'kinda cut loose' (Female, binge heavy, 18) when they arrive at university. So young students' first experiences of alcohol are often less than ideal as exemplified in the quotes above. This female participant noted of her own initiation 
into drinking that 'I had my year in the sixth form when I was really drunk quite a bit', but that now she feels that 'you don't have to be wasted, you can have a couple of drinks and still have fun' (Female, binge heavy, 18). So she has aged out of disastrous drinking practices like 'sculling' a bottle of wine and vomiting in the sink, as she already has drinking experiences (and disasters) from previous years. Therefore, negotiating or resisting different or new cultures of intoxication may be especially challenging for inexperienced drinkers.

Additionally, in terms of drinking harms, some of the participants noted that limits around alcohol had to be experienced to be learnt, and that experiencing negative consequences personally or witnessing friends and peers having bad experiences while drinking, helped young drinkers to learn what not do:

How much you drink, definitely. You kind of, you get to know your limit. You get to know how much you can drink and still have a good time and how much is too much to know that you'll feel awful for the next day. (Grace, binge moderate, 18 )

I think that people try to ... they try to limit it before people actually know the full experience ...I know it sounds odd, but I know so many people's parents will limit the amount of alcohol their children drink...eventually there will be one time and you will learn, and even then you'll never do it again, or you'll see someone who does it and you'll never do it again. Like if a friend is vomiting for 3 hours or if a friend blacks out, clearly you are not going to try it. So I think it is a learned thing. (Grace, binge moderate, 18)

Earlier research with young New Zealand drinkers (Hutton 2012) also noted this issue: that young people need to learn to drink 'properly', akin to Becker's (1963) cannabis users and the learned experience of 'getting high'. Underage drinking in a UK context is also noted as a learning phase where young people learn how to drink and get drunk as well as learning about their limits in relation to alcohol consumption (Christmas and Seymour 2014). Therefore the cultures of intoxication that young people are socialised into, interact with and experience have significance in terms of their future drinking practices. The issues raised in the previous quotes also demonstrate the difficulties in developing harm reduction campaigns and interventions, as personal experience (i.e. you have to make mistakes to learn) is cited as a key factor in 'learnt' drinking practices, a philosophy which is highly problematic to intervene in. Furthermore the difficulties of engaging young people in harm reduction campaigns have been noted (Hutton 2012; Nicolls 2012). 


\section{CONCLUSION}

Although the small sample size is a limitation of this exploratory study, a number of discussion points arise from analysis of the data. The argument presented in this article constructs university student drinking cultures, as influenced by and embedded in a wider overarching national culture of intoxication. A clear, overarching, New Zealand culture of intoxication was identified that was absorbed, shaped, resisted and experienced by the research participants. However, this culture of intoxication is not the same for all of the students in this study: they bring with them the cultures of intoxication that they have previously been socialised into, influenced by parents, peers, gender, and geographical location. Therefore, the suggestion is that cultures of intoxication are diverse and have multiple, interconnected tiers: there is a continuum of intoxication that young people have to negotiate in their drinking practices. It would also appear that university student cultures of intoxication are a sub-set of wider youth drinking cultures, and that these students as a group sit outside the patterns of declining use and abstinence identified by researchers in a New Zealand and a global context (Fuller 2010; Fuller and Hawkins 2014; Livingston 2014; Measham 2008; Ministry of Health 2013). For non- or light drinkers fitting into student cultures of intoxication is problematic, and as Järvinen and Gundelach $(2007,68)$ note 'cautious drinkers may be under the greatest pressure' to embed themselves into their peers' drinking practices.

The wider New Zealand culture of intoxication was identified and articulated throughout the interviews, with some students being highly critical of their parent's generation for modelling poor drinking practices and attitudes toward alcohol. This reiteration (Butler 1990) of the acceptability of alcohol and intoxication creates an environment where young people feel intense peer and societal pressure to interact with, and conform to, cultures of intoxication. The symbolic capital of alcohol consumption was clearly identified by participants in this study, and several factors influenced participants' levels of engagement with and resistance to cultures of intoxication. For example, those who made a conscious choice to disengage from student (and wider) drinking cultures went to extraordinary lengths to 'pass' as drinkers (and so retain symbolic capital), related to fitting in with peers and avoiding negative attention from others who may be critical of their non or light drinking practices. Other participants in this study merged with local student cultures of intoxication (influenced by the wider New Zealand drinking culture) in varying ways. Some engaged wholeheartedly, relating fairly heavy levels of consumption while others merged at the margins, displaying a heavier drinking persona than was actually the case. 
The strategies employed by these participants suggests that the symbolic capital of alcohol consumption as well as its function in young people's drinking and friendship groups renders it a necessary part of group belonging in this particular university context. That participants who were non- or light drinkers recognised the symbolic capital attached to alcohol consumption, to the extent that they mimicked a drinking identity, arguably demonstrates the pervasiveness and centrality of alcohol in young people's lives. It is evident in this sample that young people's engagement with alcohol consumption and the symbolic capital it can afford drinkers is complex and often contradictory.

However, that some young people disengage from cultures of intoxication is a topic worthy of further study, alongside the statistics that demonstrate levels of youth drinking are declining (Clark et al. 2013; Fuller 2010; Fuller and Hawkins 2014; Measham 2008), as well as studies demonstrating that there is a consistent minority of university students who are non- or light drinkers (Conroy and de Visser 2014; Romo 2012). For example, is it the case that young teenagers eventually merge with or immerse themselves in cultures of intoxication as Livingston (2014) perhaps suggests, or do they remain on the margins as abstainers or light, infrequent drinkers? As noted earlier young people do abstain from drinking and often construct alternative non-drinking identities, happy to be considered 'outside the norm' (Fry 2010; Herring et al. 2014; Nairn et al. 2007; Zajdow and MacLean 2014).

Some areas related to harm reduction highlighted by the interview data may warrant further research and investigation. For example, the theme of 'inexperienced drinking disasters': public health agencies could perhaps target first drinking experiences, and work with young people to prevent or limit inexperienced drinking disasters' and 'symbolic failures'. In addition the task of making new friends and merging with student cultures of intoxication might also be a useful focus for health promotion efforts: how to gain symbolic capital in student cultures of intoxication without suffering adverse consequences. These preliminary suggestions need further exploration and are noted here as areas for more detailed research and attention. Further, as documented elsewhere (Aldridge 2008; Boys et al. 1999; Hutton 2012; Kuntsche et al. 2005; Measham 2006) a key issue for health promotion agencies is the pleasure involved in alcohol (and other drug) consumption, as well as the problematic issue of unsettling the symbolic capital associated with alcohol (and other drugs) in young people's friendship groups. However, by viewing drinking as a socially constructed practice (Supski et al. 2016), as involving more than the individual drinker, and focusing on the 'processes and relationships' (Blue, Shove, Carmona, and Kelly 2016, 38 cited in Supski et al. 2016,3) that make 
up the social practice of university drinking, a more nuanced view of student drinking cultures may emerge. Therefore moving away from focusing on individual drinking practices opens up the possibility that alternative 'practices' can be developed, or that drinking as a social practice could be intervened in, modified and changed (Supski et al. 2016). Scholars in this area also make the point that health promotion efforts to stimulate moderate drinking fail to provide information to young drinkers on how they can manage their non or light drinking status (Conroy and de Visser 2014). How can students comfortably be non- or light drinkers when the norms and values of their peers so intensely focus on heavy alcohol consumption, and often denigrate those who sit outside of group norms?

The diversity of the cultures of intoxication experienced by young people suggested here increases the problematic nature of developing such harm reduction interventions. Given the multi-layered nature of cultures of intoxication, the pleasures of engaging with them, and the fluidity of young people's drinking practices, health promotion efforts face the ever present and thorny questions of how to address diverse and problematic issues in simple, effective, non-judgmental ways. In addition, the merging of several different cultures of intoxication in the heady environment of university halls noted by this sample, is likely to present ongoing issues for students and university administrations alike.

\section{ACKNOWLEDGEMENTS}

The author would like to acknowledge the Victoria University Reduce Harm Group that funded the research this article is based on, as well as Dr Sarah Wright Monod who transcribed the interviews as a research assistant for this study. Thanks also to the anonymous reviewers of this article and the journal editor for their helpful and constructive comments.

NOTES

1 Fiona Hutton is a senior lecturer in Criminology at the Institute of Criminology, Victoria University, Wellington, New Zealand.

Email: fiona.hutton@vuw.ac.nz.

2 Participants self-defined what a 'drink' was, so the number of drinks may not refer to standard drinks e.g., they may be referring to self-poured measures in private settings, rather than standard drinks served at licensed establishments. 
3 A 'goon' or 'goon sack' is a slang term for the bag inside a box of wine or ready mixed spirits, so this participant is saying he drank a whole box of alcohol (approximately 3 litres).

4 'Sculling' refers to the practice of drinking alcohol very quickly.

\section{REFERENCES}

Aldridge, J. 2008. 'A Hard Habit to Break? A Role for Substance Use Education in the New Millennium.' Health Education 3:185-188.

Babor, T., R. Caetano, S. Casswell, G. Edwards, N. Giesbrecht, K. Graham, and I. Rossow. 2010. Alcohol: No Ordinary Commodity Research and Public Policy (2nd ed). Oxford: Oxford University Press.

Bailey, L. 2012. Young Women and the Culture of Intoxication: Negotiating Classed Femininities in the Postfeminist Context, $\mathrm{PhD}$ thesis. England: University of Bath, School of Management.

Becker, H. 1963. Outsiders: Studies in the Sociology of Deviance. London: Free Press of Glencoe.

Bourdieu, P. 1989. 'Social Space and Symbolic Power.' Sociological Theory 7:14-25.

Boys, A., J. Marsden, J. Fountain, P. Griffiths, G. Stillwell, and J. Strang. 1999. 'What Influences Young People's Use of Drugs? A Qualitative Study of Decision Making.' Drugs: Education, Prevention and Policy 3:373-387.

Brain, K.J. 200o. 'Youth, Alcohol and the Emergence of the Postmodern Alcohol Order. Occasional paper No. 1'. London: Institute of Alcohol Studies.

Braun, V., \& V. Clarke, 2006. 'Using Thematic Analysis in Psychology'. Qualitative Research in Psychology 3 (2):77-101.

Bryman, A., and R.G. Burgess. 1994. Analyzing Qualitative Data. London: Routledge

Butler, J. 1990. Gender Trouble: Feminism and the Subversion of Identity. New York: Routledge. 
Christmas, S., and F. Seymour. 2014. Drunken Nights Out: Motivations, Norms and Rituals in the Night-Time Economy. London: Drinkaware.

Clark, T.C., T. Fleming, P. Bullen, S. Denny, S. Crengle, B. Dyson, S. Fortune, M. Lucassen, R. Peiris-John, E. Robinson, F. Rossen, J. Sheridan, T. Teevale, and J. Utter. 2013. Youth '12 Overview: the Health and Wellbeing of New Zealand Secondary School Students in 2012. Auckland: the University of Auckland.

Connell, R. 1995. Masculinities. Cambridge: Polity Press.

Conroy, D., and R. de Visser. 2014. 'Being a Non-Drinking Student: an Interpretive Phenomenological Analysis'. Psychology and Health 29 (5):536-551.

Day, K., B. Gough, \& M. McFadden. 2003. 'Women Who Drink and Fight: A DiscourseAnalysis of Working-Class Women's Talk'. Feminism \& Psychology, $13(2): 141-158$.

Demont, J., and M. Järvinen. 2011. 'Social Capital as Norms and Resources: Focus Groups Discussing Alcohol'. Addiction Research and Theory 19 (2):91-101.

De Visser R.O., and J.A. Smith. 2007. 'Young Men's Ambivalence Toward Alcohol.' Social Science \& Medicine 64 (2):350-362.

Douglas, Mary. 1987. Constructive drinking: perspectives on drink from anthropology. Cambridge, New York: Cambridge University Press.

Eldred-Grigg, S. 1984. Pleasures of the Flesh: Sex and Drugs in Colonial New Zealand 1840-1915. Wellington: Reed Ltd.

Emslie, C., K. Hunt, and A. Lyons. 2012. 'Older wiser? Men's and Women's Accounts of Drinking in Early Mid-Life'. Sociology of Health and Illness 34 (4):481-496.

Fuller. 2010. Smoking Drinking and Drug Use Among Young People in England in 2010. London: Health and Social Care Information Centre.

Fuller, E., and V. Hawkins. 2013. Smoking Drinking and Drug Use Among Young People in England in 2013. London: Health and Social Care Information Centre.

Fry, M-L. 2010. 'Countering Consumption in a Culture of Intoxication' Journal of Marketing Management 26 (13-14):1279-1294. 
Gordon, R., D. Heim and S. MacAskill. 2012. 'Rethinking Drinking Cultures: A Review of Drinking Cultures and a Reconstructed Dimensional Approach.' Public Health 126:3-11.

Graham, K., and S. Wells. 2003. "Somebody's Gonna Get their Head Kicked in Tonight!" Aggression Among Young Males in Bars - A Question of Values?. British Journal of Criminology 43(3):546-566.

Griffin, C., A. Bengry-Howell, C. Hackley, W. Mistral, and I. Szmigin. 2009. 'The Allure of Belonging: Young People's Drinking Practices and Collective Identification'. In Identity in the $21^{\text {st }}$ Century: New Trends in Changing Times, edited by Wetherell, M, 213-230, Basingstoke: Palgrave MacMillan.

Griffin, C., I. Szmigin, A. Bengry-Howell, C. Hackley and W. Mistral. 2013. 'Inhabiting the Contradictions: Hypersexual Femininity and the Culture of Intoxication Among Young Women in the UK'. Feminism and Psychology, 23(2):184-206.

Hadfield, P. 2006. Bar wars: Contesting the Night in Contemporary British Cities. Oxford: Oxford University Press.

Herring, R., M. Bayley and R. Hurcombe. 2014.“'But No One Told Me It's Okay Not To Drink": A Qualitative Study of Young People Who Drink Little or No Alcohol'. Journal of Substance Use 19 (1-2): 95-102.

Hernandez, L., R. Leotini, and K. Harley. 2013 'Alcohol, University Students, and Harm Minimization Campaigns: "A Fine Line Between a Good Night Out and a Nightmare". Contemporary Drug Problems 40:157-189.

Hutton. F. (2009). 'New Zealand'. In Nightlife and Crime: Social Order and Governance in International Perspective, edited by Hadfield, P, 293-305. Oxford: Oxford University Press.

Hutton.F. (2012). 'Harm Reduction, Students and Pleasure: An Examination of Student Responses to a Binge Drinking Campaign'. International Journal of Drug Policy 23 (3):229-235.

Hutton.F., S. Wright and E. Saunders. 2013. 'Cultures of Intoxication: Young Women, Alcohol and Harm Reduction. Contemporary Drug Problems 40 (4): 451480 . 
Hutton. F. and S. Wright. 2015. "You Don’t Ditch Your Girls': Young Māori and Pacific Women and the Culture of Intoxication', Critical Public Health, 25(1):101-119.

Järvinen, M. and P. Gundelach. 2007. 'Teenage Drinking, Symbolic Capital and Distinction'. Journal of Youth Studies 10 (1):55-71.

Kuntsche, E., R. Knibbe, G. Gmel and R. Engels. 2005. 'Why do Young People Drink? A Review of Drinking Motives.' Clinical Psychology Review 25: 841-86.

Kypri, K., J.Langley, R. McGee, J. Saunders and S.Williams. 2002. 'High Prevalence, Persistent Hazardous Drinking in New Zealand Tertiary Students'. Alcohol and Alcoholism 37:457-464.

Kypri, K., M. Paschall, J. Langley, J. Baxter, M. Cashell-Smith and B. Bourdeau. 2009. 'Drinking and Alcohol-Related Harm Among New Zealand University Students: Findings from a National Web-Based Survey. Alcoholism: Clinical \& Experimental Research 32 (2):307-314.

Karam, E., K. Kypri and M. Salamoun. 2007.'Alcohol Use Among College Students: an International Perspective.' Current Opinion Psychiatry 209:213-221.

Kypri, K., J.M. Paschall, J.D. Langley, J. Baxter and B. Bourdeau. 2010. 'The Role of Drinking Locations in University Student Drinking: Findings from a National Web-Based Survey'. Drug and Alcohol Dependence 111:38-43.

Livingston, M. 2014. 'Trends in Non-Drinking Among Australian Adolescents.' Addiction 109:922-929.

Lunnay, B., P. Ward and J. Borlagdan. 2011. 'The Practise and Practice of Bourdieu: The Application of Social Theory to Youth Alcohol Research.' International Journal of Drug Policy 22: 428-436.

Lyons, A. \& S. Willot. 2008. 'Alcohol Consumption, Gender Identities and Women's Changing Social Positions' Sex Roles 59: 694-712.

McEwan, B., M. Campbell, A. Lyons and D. Swain. 2013. Pleasure, Profit and Pain: Alcohol in New Zealand and the Contemporary Culture of Intoxication. Hamilton: University of Waikato Faculty of Arts \& Social Sciences. 
McCreanor, T., H. Moewaka Barnes, H. Kaiwai, S. Borell and A. Gregory. 2008. 'Creating Intoxigenic Environments: Marketing Alcohol to Young People in Aotearoa New Zealand.' Social Science and Medicine 67: 938-946.

McCreanor, T. A. Lyons, C. Griffin, I. Goodwin, H. Moewaka Barnes and F. Hutton. 2013. Youth Drinking Cultures, Social Networking and Alcohol Marketing: Implications for Public Health, Critical Public Health 23 (1):110-120.

Measham, F. and K. Brain. 2005. "'Binge" Drinking, British alcohol Policy and the New Culture of Intoxication.' Crime, Media and Culture: An international Journal 1:262-283.

Measham, F. 2006. 'The New Policy Mix: Alcohol, Harm Minimisation and Determined Drunkenness in Contemporary Society.' The International Journal of Drug Policy 17:258-268.

Measham, F. 2008. 'The Turning Tides of Intoxication: Young People's Drinking in Britain in the 200os. Health Education 3:207-222.

Ministry of Health. 2013. Hazardous Drinking in 2011/12: Findings from the New Zealand Health Survey. Wellington: Ministry of Health.

Moewaka Barnes, H., T. McCreanor, I. Goodwin, A. Lyons, C. Griffin and F. Hutton. 2016. 'Alcohol and Social Media: Drinking and Drunkenness While Online'. Critical Public Health 26 (1): 62-76.

Nicholls, J. 2012. 'Everyday, Everywhere: Alcohol Marketing and Social Media: Current Trends.' Alcohol and Alcoholism. http://alcalc.oxfordjournals.org/

Nairn, K., J. Higgins, B. Thompson, M. Anderson and N. Fu. 2007. "It's Just Like the Teenage Stereotype, You Go Out and Drink and Stuff”: Hearing from Young People Who Don't Drink.' Journal of Youth Studies 9 (3):287-304.

Phillips, J. 1987. A Man's Country: the Image of the Pākehā Male. Auckland: Penguin.

Romo. L.K., 2012. “Above the Influence”: How College Students Communicate about the Healthy Deviance of Alcohol Abstinence. Health Communication $27(7): 672-681$.

Ross-Houle, K., A. Atkinson and H. Sumnall. 2015. 'The Symbolic Value of Alcohol: the Importance of Alcohol Consumption, Drinking Practices and Drink- 
ing Spaces in Classed and Gendered Identity Construction'. In Drinking Dilemmas: Space, Culture and Identity, edited by T. Thurnell-Read, 28-44, Florence: Taylor Francis.

Sheehan, M. and D. Ridge. 2001. "You Become Really Close.... You Talk About the Silly Things You Did, and We Laugh"': The Role of Binge Drinking in Female Secondary Students' Lives.' Substance Use \& Misuse 36 (3):347-372.

Suaalii-Sauni, T., K. Samu, l. Dunbar, J. Pulford, and A. Wheeler. 2012. 'A Qualitative Investigation into Key Cultural Factors that Support Abstinence or Responsible Drinking Amongst Some Pacific Youth Living in New Zealand.' Harm Reduction Journal 9 (36):1-12.

Supski, S., J. Lindsay and C. Tanner. 2016. 'University Students' Drinking as a Social Practice and the Challenge for Public Health. Critical Public Health. doi: http://dx.doi.org/10.1080/09581596.2016.11900o1

Szmigin, I., C. Griffin, W. Mistral, A. Bengry-Howell, L. Weale, and C. Hackley, 2008. 'Re-Framing "Binge Drinking" as Calculated Hedonism: Empirical Evidence from the UK.' International Journal of Drug Policy 19 (5):359-366.

Thurnell-Read, T. 2015. 'An Introduction to Drinking Dilemmas: Space, Culture and Identity'. In Drinking Dilemmas: Space, Culture and Identity, edited by T. Thurnell-Read, 1-12, Florence: Taylor Francis.

Tutenges, S. and S. Sandberg. 2013. 'Intoxicating Stories: The Characteristics, Contexts and Implications of Drinking Stories Among Danish Youth.' International Journal of Drug Policy 24: 538-544.

Wechsler, H., J.E. Lee, M. Kuo, M. Seibring, T.F. Neslon and H. Lee. 2002. 'Trends in College Binge Drinking During a Period of Increased Prevention Efforts.' JAM Coll Health 50:203-217.

Zajdow, G., and S. MacLean. 2014. “I Just Drink for that Tipsy Stage”: Young Adults and Embodied Management of Alcohol Use.' Contemporary Drug Problems 41(4):522-535. 